\title{
Weapons Effect
}

\author{
ARLIN J. BENJAMIN, JR. \\ University of Arkansas-Fort Smith, USA
}

Weapons are ubiquitous in the mass media and in everyday life. Does even short-term exposure to weapons lead to increased aggression? In the late 1960s, two researchers attempted to answer that question. Berkowitz and LePage (1967) published an experiment in which participants were exposed to either guns or badminton racquets after experiencing one electric shock (low provocation) or seven electric shocks (high provocation). The highly provoked participants who experienced short-term exposure to the rifles gave more shocks to their partner (thus indicating a higher level of aggression) than participants in any of the other treatment conditions. Since then, this phenomenon has been known as the weapons effect. In the ensuing decades, researchers interested in the weapons effect have examined short-term exposure not only to guns, but also knives and even Tasers on aggressive behavioral outcomes (Ariel et al., 2019; Benjamin, Kepes, \& Bushman, 2018). This entry describes the potential influence of weapons on aggressive behavioral outcomes, explanations for why the weapons effect may occur, potential underlying processes, and the ongoing controversy regarding the extent to which the weapons effect is a valid area of inquiry.

During the 1970s and 1980s there were numerous attempts to replicate the initial weapons effect experiment (Benjamin, 2019). Although there were some apparent successful replications of the weapons effect (e.g., Leyens \& Parke, 1975), there were also a number of studies reporting non-replication (e.g., Buss, Booker, \& Buss, 1972). Critics initially argued that there were characteristics of the design of the original Berkowitz and LePage (1967) experiment which would lead participants to become suspicious and guess the hypothesis, or which would make participants more aware that they were being evaluated, and hence increase evaluation apprehension. These experimental artifacts were proposed to influence participants to behave more aggressively when exposed to weapons, thus invalidating the conclusions of the original Berkowitz and LePage (1967) experiment. Concerns regarding participant suspicion and evaluation apprehension appeared to be addressed in a series of experiments conducted in the mid-1970s (e.g., Simons \& Turner, 1976) in which participants who were either suspicious or made aware that they were being evaluated showed a decrease in aggressive behavior, even when primed with weapons. However, in the conditions in which participants were blind to the hypothesis and were not given cues to make them apprehensive, they responded to weapons with increased aggression. In other words, under conditions in which participants were unaware of the hypothesis and not apprehensive, Simons and Turner (1976) appeared to replicate the findings of Berkowitz and LePage (1967). During this time, there were reports of mixed findings in experiments 
conducted in field settings (e.g., Turner, Layton, \& Simons, 1975), as well as experiments in which children were participants, with images of weapons used instead of real weapons, and with aggressive behavioral measures other than electric shocks (see Benjamin et al., 2018). Some replications appeared to be successful, but others were not. Even though the body of published research on the weapons effect appeared ambiguous, an initial meta-analysis suggested that overall the weapons effect was robust under conditions in which participants were highly provoked (Carlson, Marcus-Newhall, \& Miller, 1990).

In the 1990s, researchers began to explore more thoroughly the underlying processes that might explain the weapons effect. Much of this research was based on theories such as the general aggression model (Anderson \& Bushman, 2002) or the cognitive neoassociation model (Berkowitz, 2012). According to these theoretical models, weapons prime the accessibility of aggressive thoughts, leading to a tendency to make primary threat appraisals, which would then influence the likelihood of an aggressive behavioral response (Benjamin \& Bushman, 2016). Initial cognitive priming experiments in the 1990s were successful (e.g., Anderson, Benjamin, \& Bartholow, 1998), and appear to have been successfully replicated over the ensuing two decades (Benjamin et al., 2018). Research on primary threat appraisal has shown that individuals show increased attention to the sight of weapons much the way individuals respond to the sight of natural threats such as venomous snakes and spiders (Benjamin \& Bushman, 2016).

Since the 1990s, given the apparent success of cognitive priming experiments, the weapons effect has been treated as an established phenomenon. However, more recent evidence raised questions about the weapons effect. The most recent meta-analysis examining the weapons effect (Benjamin et al., 2018) suggested that although the mere presence of weapons appeared to reliably increase accessibility of aggressive cognition and hostile threat appraisals, the available literature suggested that the influence of the mere presence of weapons on aggressive behavioral outcomes was at best inconclusive. Although the basic mean effect size for the influence of weapons on aggressive behavior was noticeably positive, a battery of tests designed to adjust for the influence of publication bias showed the mean effect size could be close to zero. The meta-analysis concluded that weapons effect research involving behavioral outcomes in particular should be interpreted cautiously. Indeed the findings from Benjamin et al. (2018) are similar to those of other recent media violence meta-analyses employing similar methods of adjusting for the influence of publication bias (e.g., Hilgard, Engelhardt, \& Rouder, 2017).

Although there is renewed skepticism about the validity of the line of research originally begun by Berkowitz and LePage (1967), there have been some recent successful attempts to demonstrate a weapons effect on aggressive behavioral outcomes. What these recent studies have in common is an effort to increase the ecological validity of the experimental settings and measurements. For example, Bushman, Kerwin, Whitlock, and Weisenberger (2017) found some evidence that individuals operating driving simulators containing guns were significantly more likely to drive aggressively (e.g., speed, follow other drivers too closely) than individuals operating driving simulators containing badminton racquets. Similarly, Ariel et al. (2019) found evidence that police officers in the City of London who had been randomly assigned to visibly carry Tasers 
were significantly more likely to be assaulted by suspects than police officers who had been randomly assigned to not carry Tasers. Although each of these experiments has its limitations, including small sample (Bushman et al., 2017) and arguably small effect size (Ariel et al., 2019), these more ecologically valid experiments show a potential way forward for researchers interested in more thoroughly addressing this particular line of research. Finally, it is worth noting that controversy surrounding the validity of the weapons effect is embedded within a context in which there is renewed questioning about the replicability of classic research more generally (e.g., Open Science Collaboration, 2015). One weapons effect researcher recommended utilizing a registered replication report (RRR) approach to lab research on the weapons effect in which research protocols are preregistered, conducted across multiple labs, resulting in large enough samples to detect potentially small effect sizes with greater accuracy (Benjamin, 2019).

SEE ALSO: General Aggression Model; Hostile Media Effect; Questionable Research Practices: $p$-Hacking, Replication, and Fraud

\section{References}

Anderson, C. A., Benjamin, A. J., Jr., \& Bartholow, B. D. (1998). Does the gun pull the trigger? Automatic priming effects of weapon pictures and weapon names. Psychological Science, 9, 308-314. doi:10.1111/1467-9280.00061

Anderson, C. A., \& Bushman, B. J. (2002). Human aggression. Annual Review of Psychology, 53, 27-51. doi:10.1146/annurev.psych.53.100901.135231

Ariel, B., Lawes, D., Weinborn, C., Henry, R., Chen, K., \& Sabo, H. B. (2019). The "less-than-lethal weapons effect"-introducing TASERs to routine police operations in England and Wales: A randomized controlled trial. Criminal Justice and Behavior, 46, 280-300. doi:10.1177/0093854818812918

Benjamin, A. J., Jr. (2019). The weapons effect. National Social Science Journal, 52(1), 1-6.

Benjamin, A. J., Jr., \& Bushman, B. J. (2016). The weapons priming effect. Current Opinion in Psychology, 12, 45-48. doi:10.1016/j.copsyc.2016.05.003

Benjamin, A. J., Jr., Kepes, S., \& Bushman, B. J. (2018). Effects of weapons on aggressive thoughts, angry feelings, hostile appraisals, and aggressive behavior: A meta-analytic review of the weapons effect literature. Personality and Social Psychology Review, 22(4), 347-377. doi:10.1177/1088868317725419

Berkowitz, L. (2012). A cognitive-neoassociation theory of aggression. In P. A. M. van Lange, A. W. Kruglanski, \& E. T. Higgins (Eds.), Handbook of theories of social psychology (pp. 99-117). Thousand Oaks, CA: Sage. doi:10.4135/9781446249222.n31

Berkowitz, L., \& LePage, A. (1967). Weapons as aggression-eliciting stimuli. Journal of Personality and Social Psychology, 7, 202-207. doi:10.1037/h0025008

Bushman, B. J., Kerwin, T., Whitlock, T., \& Weisenberger, J. M. (2017). The weapons effect on wheels: Motorists drive more aggressively when there is a gun in the vehicle. Journal of Experimental Social Psychology, 73, 82-85. doi:10.1016/j.jesp.2017.06.007

Buss, A. H., Booker, A., \& Buss, E. (1972). Firing a weapon and aggression. Journal of Personality and Social Psychology, 22, 296-302. doi:10.1037/h0032869

Carlson, M., Marcus-Newhall, A., \& Miller, N. (1990). Effects of situational aggression cues: A quantitative review. Journal of Personality and Social Psychology, 58, 622-633. doi:10.1037/0022-3514.58.4.622 
Hilgard, J., Engelhardt, C. R., \& Rouder, J. N. (2017). Overstated evidence for short-term effects of violent games on affect and behavior: A reanalysis of Anderson et al. (2010). Psychological Bulletin, 143, 757-774. doi:10.1037/bul0000074

Leyens, J.-P., \& Parke, R. D. (1975). Aggressive slides can induce a weapons effect. European Journal of Social Psychology, 5, 229-236. doi:10.1002/ejsp.2420050207

Open Science Collaboration. (2015). Estimating the reproducibility of psychological science. Science, 6251. doi:10.1126/science.aac4716

Simons, L. S., \& Turner, C. W. (1976). Evaluation apprehension, hypothesis awareness, and the weapons effect. Aggressive Behavior, 2, 77-87. doi:10.1002/1098-2337(1976)2:1<77::AIDAB2480020108>3.0.CO;2-A

Turner, C. W., Layton, J. F., \& Simons, L. S. (1975). Naturalistic studies of aggressive behavior: Aggressive stimuli, victim visibility, and horn honking. Journal of Personality and Social Psychology, 31, 1098-1107. doi:10.1037/h0076960

\section{Further reading}

Toch, H., \& Lizotte, A. J. (1992). Advocating gun control. In P. Suedfeld \& P. E. Tetlock (Eds.), Psychology and social policy (pp. 223-249). New York, NY: Hemisphere.

Turner, C. W., \& Leyens, J.-P. (1992). The weapons effect revisited: The effects of firearms on aggressive behavior. In P. Suedfeld \& P. E. Tetlock (Eds.), Psychology and social policy (pp. 201-222). New York, NY: Hemisphere.

Turner, C. W., Simons, L. S., Berkowitz, L., \& Frodi, A. (1977). The stimulating and inhibiting effects of weapons on aggressive behavior. Aggressive Behavior, 3, 355-378. doi:10.1002/10982337(1977)3:4<355::AID-AB2480030405>3.0.CO;2-G

Arlin J. Benjamin, Jr. earned his $\mathrm{PhD}$ in Social Psychology from the University of Missouri-Columbia in 2000. He is currently an associate professor in the Department of Behavioral Sciences at the University of Arkansas-Fort Smith. His research concentrates on the question of the extent to which aggression-related situational cues (e.g., violent video games, weapon images) influence aggressive cognitions, behaviors, and aggression-related attitudes, as well as individual differences predicting aggressive behavior and attitudes toward violence. Increasingly, his work is concentrating on the validity of measures of aggression-related cognitive and behavioral outcomes. 